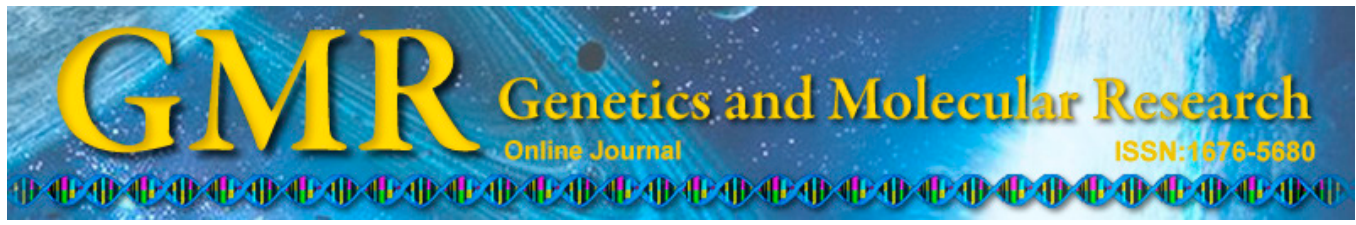

\title{
Expression patterns of Doppel in differential ovine PRNP genotypes: quantification using real-time RT-PCR
}

\author{
C. Wang ${ }^{1}$, C.-L. Zhao ${ }^{1,2}$, L. Liu ${ }^{1}$, R. Wu ${ }^{1}$ and X.-L. Zhang ${ }^{1}$ \\ ${ }^{1}$ College of Veterinary Medicine, Gansu Agricultural University, Lanzhou, \\ China \\ ${ }^{2}$ Animal Husbandry and Veterinary Bureau of Tianshui City, Tianshui, China
}

Corresponding author: R. Wu

E-mail: wurun@gsau.edu.cn

Genet. Mol. Res. 14 (4): 12152-12158 (2015)

Received January 25, 2015

Accepted June 26, 2015

Published October 9, 2015

DOI http://dx.doi.org/10.4238/2015.October.9.3

\begin{abstract}
Doppel is a homologue of cellular prion protein $(\operatorname{PrP})-$ like protein $\left(\mathrm{PrP}^{\mathrm{C}}\right)$. Different tissue samples were collected from the central nervous system plus four regions of lymphoid system, eleven regions of digestive tract and two reproductive organs from four ARR/ARQ and four ARH/ARQ sheep, genotypes of the PrP gene. Total RNA was isolated from these samples, and Doppel mRNA was quantified by real-time RT-PCR using SYBR Green. Doppel mRNA expression was higher in the ovary, hypothalamus and brain than in other tissues, and it significantly differed between the two genotypes in brain, ileum, cecum, rectum, colon, and uterus. This study demonstrated that Doppel mRNA expression in sheep with ARR/ARQ or ARH/ARQ genotypes was very different. These findings could be helpful in future studies of the relationship between PrP and Doppel.
\end{abstract}

Key words: Ovine; mRNA expression; Real-time quantitative RT-PCR; Doppel gene; PRNP genotypes 


\section{INTRODUCTION}

Doppel is encoded by the Dpl gene, located downstream of the prion protein (PrP) gene (PRNP), and Doppel shares significant biochemical and structural homology with PrP (Li et al., 2000). In sheep, susceptibility to scrapie is strongly associated with polymorphisms at codons 136 [alanine (A) or valine (V)], 154 [arginine $(\mathrm{R})$ or histidine $(\mathrm{H})$ ] and 171 [glutamine $(\mathrm{Q}), \mathrm{R}$, or $\mathrm{H}]$ in the host prion protein gene which encodes PrP (Goldmann et al., 1990; Hunter et al., 1996). In general, the ovine alleles VRQ and ARQ seem to be related to a higher susceptibility to scrapie, while the alleles ARR and AHQ are associated with lower susceptibility. Doppel mRNA expression in humans (Makrinou et al., 2002) and mice (Li et al., 2000) has been shown to have spatial and temporal patterns, as determined by Northern blot or in situ hybridization, and Doppel mRNA levels in golden hamster have been shown to be tissuespecific using real-time RT-PCR ( $\mathrm{Li}$ et al., 2008). However, the expression patterns of the Doppel gene in differential ovine PRNP genotypes were previously unknown. In this study, Doppel mRNA in sheep with different PRNP genotypes were quantified by real-time RT-PCR using SYBR Green, and the results could explain the patterns of scrapie disease progression and relationship between Doppel expression levels and PRNP genotypes.

\section{MATERIAL AND METHODS}

\section{Animals and tissue samples}

Two types of prevalent heterozygous genotype were studied in healthy Small-tailed Han sheep in Gansu Province of China (Zhao et al., 2012). Four ewes were ARR/ARQ, a genotype resistant to scrapie (Caplazi et al., 2004), and four ewes were ARH/ARQ, a genotype with intermediate susceptibility to scrapie (O'Doherty et al., 2002). The age of the animals ranged from three to four years old. All animals were negative for TSE in brain, determined by the $\mathrm{PrP}^{\mathrm{Sc}}$ detection kit (Platelia ${ }^{\circledR} \mathrm{BSE}$ ) (Bio-Rad, Hercules, CA, USA). The animals were slaughtered and tissue samples from the same region of cerebrum, cerebellum, thalamus, brain stem and spinal cord with respect to central nervous systems, and spleen, tonsils, mandibular lymph node, inguinal lymph node, intestinal lymph node, heart, lung, kidney, liver, pancreas, tongue, pharynx, esophagus, rumen, jejunum, duodenum, cecum, ileum, colon, rectum, mammary gland, uterus and ovary as peripheral organs were aseptically taken from each animal. All tissues were immediately frozen in liquid nitrogen and stored at $-80^{\circ} \mathrm{C}$ until RNA extraction was performed.

\section{RNA extraction and cDNA synthesis}

Total RNA was extracted from $100 \mathrm{mg}$ tissue of each sample using the TRIZOL reagent (Invitrogen, Vienna, Austria) and treated with RNase-free DNase I (TaKaRa, Japan) to remove possible contaminating DNA. The purity of the total RNA was estimated by the $\mathrm{OD}_{260} / \mathrm{OD}_{280}$ ratio (1.9-2.0). RNA concentration was determined with a spectrophotometer (GE, USA), using the $\mathrm{OD}_{260 \mathrm{~mm}}$. Constant amounts of $1000 \mathrm{ng}$ RNA were reverse-transcribed to cDNA using 200 U Reverse Transcription System SS III (Invitrogen) according to the manufacturer instructions. Six randomly chosen control samples without transcriptase (RT-negative) were used as controls for RT step. 
C. Wang et al.

\section{Construction of recombinant plasmid}

The 227-bp fragments of the target gene were amplified by the primers: 5'-ATGAGGAAACATCTGGGTGG-3' (forward); 5'-CTATTGCCCTCCACT-CCAAA-3' (reverse) in a $25.0 \mu \mathrm{L}$ reaction volume containing $1.0 \mu \mathrm{L}$ cDNA, $1.0 \mu \mathrm{L}$ of each primer $(10$ $\mathrm{pM}), 12.5 \mu \mathrm{L}$ Ex Taq mix (Takara, Japan) and $9.5 \mu \mathrm{L}$ sterile water. PCR was conducted under the following conditions: an initial denaturation at $94^{\circ} \mathrm{C}$ for $5 \mathrm{~min}$, followed by 35 cycles of $94^{\circ} \mathrm{C}$ for $30 \mathrm{~s}, 58^{\circ} \mathrm{C}$ for $45 \mathrm{~s}$ and $72^{\circ} \mathrm{C}$ for $30 \mathrm{~s}$, and a final extension at $72^{\circ} \mathrm{C}$ for $8 \mathrm{~min}$, using a thermal cycler (Bio-Rad, USA). The PCR products were analyzed by electrophoresis on a $1.5 \%$ agarose gel.

To eliminate artifacts that could arise during the PCR process, ten PCR mixtures were set up for each sample together with controls (no cDNA). PCR bands of interest were cut from the gel and purified using a commercial kit (E.Z.N.A ${ }^{\circledR}$ Gel Extraction kit, Promega, USA). The plasmid was constructed by cloning the PCR product into the pGEM-T Easy Vector (Promega, USA) according to the manufacturer guidelines and were transformed into competent DH5 $\alpha$ cells. Plasmid DNA was purified and sequenced. Purified plasmid DNA was quantified with a spectrophotometer (GE, USA), using the $\mathrm{OD}_{260 \mathrm{~nm}}$, and the copy numbers were calculated. For standard curve acquisition, six 10-fold serial dilutions of plasmid DNA from $10^{3}$ to $10^{8}$ molecules were prepared.

\section{Quantitative RT-PCR}

Real-time quantitative PCR was performed using a DNA Engine OpticonTM2 continuous fluorescence detection system (Stratagene Mx3005P) and SYBR GreenER qPCR SuperMix Universal (Invitrogen). The primers above were used to amplify cDNA of the biological sample, negative controls and six plasmid DNA standards. PCR was carried out in a real-time PCR tube. The total volume was $25.0 \mu \mathrm{L}$, which included $1.0 \mu \mathrm{L}$ plasmid DNA or $1.0 \mu \mathrm{L}$ cDNA (equivalent to $50 \mathrm{ng}$ reverse-transcribed total RNA), $12.5 \mu \mathrm{L}$ SYBR GreenER qPCR SuperMix Universal (Invitrogen), $0.5 \mu \mathrm{L}$ of each primer $(10 \mathrm{pM})$ and $10.5 \mu \mathrm{L}$ sterile water. PCR amplification was as follows: after denaturation at $95^{\circ} \mathrm{C}$ for $2 \mathrm{~min}, 35$ cycles were performed including $95^{\circ} \mathrm{C}$ for $15 \mathrm{~s}, 54^{\circ} \mathrm{C}$ for $30 \mathrm{~s}$ and elongation at $72^{\circ} \mathrm{C}$ for $30 \mathrm{~s}$. Finally a melting step was performed consisting of $10 \mathrm{~s}$ at $65^{\circ} \mathrm{C}$ and slow heating with a rate of $0.1^{\circ} \mathrm{C}$ per second up to $95^{\circ} \mathrm{C}$ with continuous fluorescence measurement.

The amount of Doppel mRNA was calculated using an absolute standard curve method. The detection limit was six molecules with the highest test linearity in the quantification range of $1.0 \times 10^{3}$ to $1.0 \times 10^{8}$ plasmid DNA molecules and qRT-PCR efficiencies and $\mathrm{R}^{2}$ values were $100 \%$ and 0.999 , respectively (Figure 1). The cDNA samples were amplified in parallel with plasmid standards in each run, and their Ct values were plotted together with the standard curves, from which the normalized Doppel mRNA copy numbers were determined.

\section{Statistical analysis}

Data were analyzed by the SPSS software (Statistical Package for the Social Sciences, version 10.0 for Windows; SPSS Inc., Chicago, IL, USA). An independent sample $t$-test was used to analyze differences in Doppel gene mRNA expression between different organs and differential sheep PRNP genotypes. 


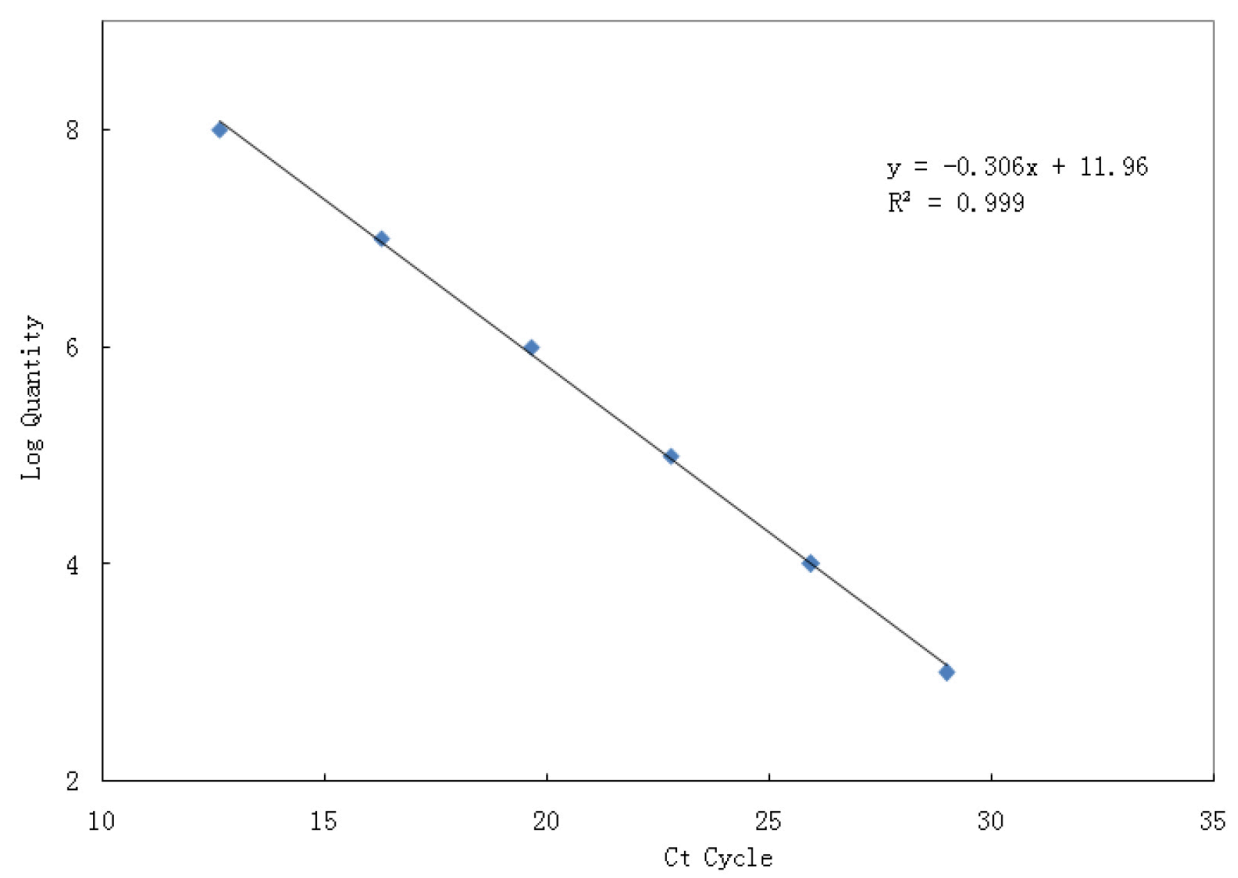

Figure 1. A representative standard curve obtained by plotting the starting copy numbers of recombinant plasmid against their cycle numbers. Six dots are calibration dilutions $\left(10^{3}-10^{8}\right.$ copies $)$ of plasmid.

\section{RESULTS}

\section{Tissue-specific expression of Doppel gene transcripts}

Doppel gene mRNA copies in different tissues of PRNP ARR/ARQ and ARH/ARQ sheep were analyzed (Figure 2) and expression levels of Doppel gene in different tissues were examined, which varied significantly (Table 1). Doppel mRNA expression level was higher in ovary and cerebrum than other tissues in sheep with the ARR/ARQ genotype. In sheep with the ARR/ARQ genotype, Doppel mRNA was highest in cerebrum and lowest in brainstem in nervous tissue, while it was highest in thalamus and lowest in brainstem in ARH/ARQ genotype sheep $(\mathrm{P}<0.05)$. Doppel mRNA expression level was moderate in spleen, tonsil, submandibular lymph node and pharynx, and low in other tissues $(\mathrm{P}<0.05)$ (Figure 2).

\section{Effect of Prnp genotype on Doppel gene expression}

Doppel gene transcript levels in the same tissue significantly differed between ARR/ ARQ and ARH/ARQ genotype sheep (Table 1). The transcript levels of Doppel gene in cecum, ileum, colon and uterus in ARR/ARQ sheep were significantly greater $(\mathrm{P}<0.05)$ than in the corresponding regions in ARH/ARQ sheep. Doppel gene mRNA expression levels in spleen, heart, tongue and rectum were significantly lower $(\mathrm{P}<0.05)$ in ARR/ARQ sheep than in ARH/ARQ sheep. 
Table 1. Detection and absolute quantification of Doppel mRNA in different tissues of ARR/ARQ and ARH/ ARQ sheep by quantitative real-time RT-PCR using an external standard curve.

\begin{tabular}{|c|c|c|c|c|c|c|c|c|}
\hline \multirow[t]{2}{*}{ Tissue } & \multicolumn{4}{|c|}{ Total RNA } & \multicolumn{4}{|c|}{ Copy/RNA } \\
\hline & ARR/ARQ & $\mathrm{CV} \%$ & ARH/ARQ & $\mathrm{CV} \%$ & ARR/ARQ & $\mathrm{CV} \%$ & ARH/ARQ & $\mathrm{CV} \%$ \\
\hline Cerebrum & 319 & 6.2 & 286 & 10.9 & $539,070-$ & 37.6 & $125,353-$ & $8.2-$ \\
\hline Cerebellum & 255 & 2.6 & 276 & 8.5 & 48,312 & 48.2 & $113,989-$ & $12.8-$ \\
\hline Brain stem & 196 & 6.0 & 229 & 10.5 & 7,446 & 20.1 & 5,228 & 47.5 \\
\hline Thalamus & 272 & 6.1 & 236 & 17.3 & $320,454-$ & 20.1 & $5,952,783+-$ & 47.7 \\
\hline Spinal cord & 101 & 28.6 & 116 & 10.4 & $9,752-$ & 20.6 & $36,320-$ & 36.6 \\
\hline Spleen & 355 & 13.9 & 370 & 17.5 & 74,574-- & 30.9 & 404,487-- & 27.1 \\
\hline Tonsils & 268 & 16.1 & 277 & 16.1 & 37,133 & 43.1 & 29,912 & 36.3 \\
\hline Mandibular lymph node & 349 & 3.8 & 334 & 9.1 & 121,162-- & 10.9 & 41,644-- & 49.1 \\
\hline Inguinal lymph nodes & 372 & 7.5 & 396 & 5.3 & 742 & 50.5 & 877 & 24.6 \\
\hline Intestinal lymph node & 317 & 8.9 & 351 & 10.6 & 168- & 2.4 & 3,005- & 55.2 \\
\hline Heart & 157 & 16.2 & 157 & 7.0 & 372 & 52.3 & 738 & 39.3 \\
\hline Lung & 338 & 3.6 & 327 & 11.1 & 486 & 36.3 & 500 & 40.1 \\
\hline Kidney & 342 & 1.4 & 334 & 13.8 & 61,913 & 52.4 & 50,373 & 32.9 \\
\hline Liver & 328 & 10.2 & 354 & 7.9 & 8,879-- & 12.3 & $2,662--$ & 12.4 \\
\hline Pancreas & 334 & 17.6 & 363 & 8.0 & 37,123-- & 24.6 & 7,319-- & 43.6 \\
\hline Tongue & 155 & 16.0 & 148 & 26.3 & 403- & 45.1 & $1,295-$ & 45.9 \\
\hline Pharynx & 141 & 15.9 & 172 & 18.3 & 12,522 & 12.5 & 25,500 & 23.1 \\
\hline Oesophagus & 154 & 6.7 & 149 & 20.4 & 1,750 & 19.8 & 1,190 & 9.1 \\
\hline Rumen & 161 & 17.5 & 192 & 16.4 & 141 & 27.7 & 116 & 26.7 \\
\hline Duodenum & 344 & 12.2 & 356 & 7.7 & $388-$ & 54.2 & $5,461-$ & 35.0 \\
\hline Rectum & 252 & 20.1 & 262 & 14.2 & $329-$ & 48.7 & $95,600-$ & 53.4 \\
\hline Cecum & 292 & 11.4 & 346 & 20.8 & 6,569- & 32.1 & 1,559- & 11.1 \\
\hline Jejunum & 340 & 7.4 & 339 & 8.6 & 273 & 47.4 & 325 & 44.0 \\
\hline Ileum & 352 & 7.0 & 312 & 9.8 & 47,472-- & 13.1 & 1,884-- & 23.6 \\
\hline Colon & 285 & 8.0 & 333 & 9.9 & 303,593- & 43.2 & 1,613- & 31.4 \\
\hline Mammary gland & 257 & 7.0 & 259 & 25.9 & 331 & 18.7 & 434 & 24.9 \\
\hline Uterus & 316 & 16.7 & 316 & 5.0 & $56,009-$ & 15.7 & $1,628-$ & 33.1 \\
\hline Ovary & 348 & 5.8 & 334 & 10.1 & $2,357,210+$ & 32.1 & $1,727,059+$ & 22.1 \\
\hline
\end{tabular}

Parameters of quantification [same as reference (Tichopad, Pfaffl et al., 2003)]. y(RNA), yield of RNA in $1 \mathrm{mg}$ of tissue; CV, coefficient of variation; copy/RNA, number of PrP mRNA copies in $1 \mathrm{ng}$ of total RNA. The sign $(+)$ indicates significant $(\mathrm{P}<0.05)$ difference between different tissues of ARR/ARQ or ARH/ARQ genotype sheep, The sign $(-)$ indicates significant $(\mathrm{P}<0.05)$ difference between same tissue of ARR/ARQ and ARH/ARQ genotype sheep. $(--)$ indicates significant difference $(\mathrm{P}<0.01)$ between the same tissue of ARR/ARQ and ARH/ARQ genotype sheep.

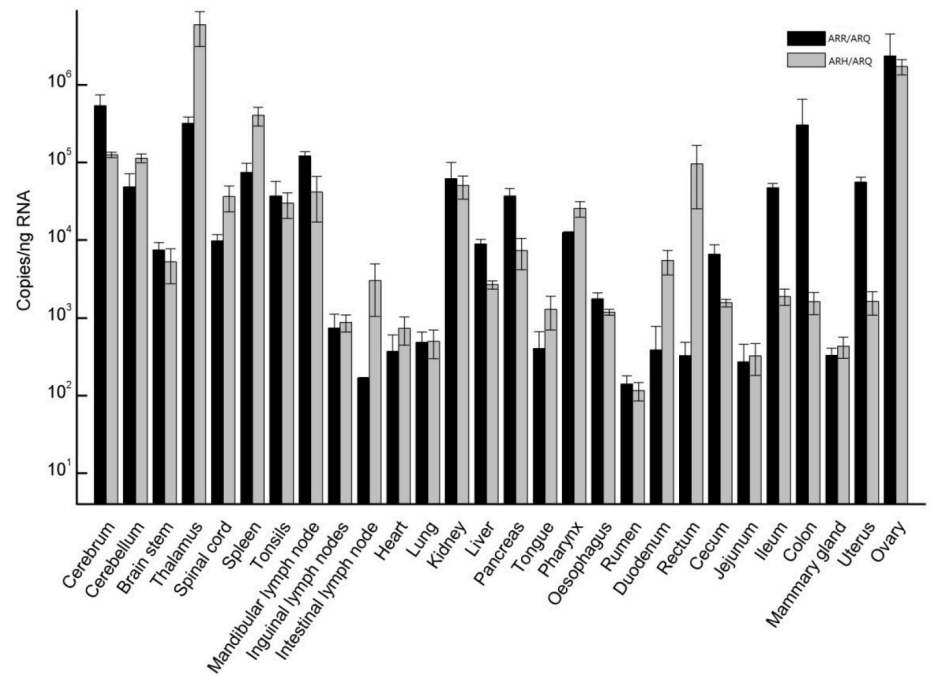

Figure 2. Doppel gene mRNA copies in 1 ng of total RNA in different tissues of ARR/ARQ and ARH/ARQ sheep. Error lines indicate SD. 


\section{DISCUSSION}

Real-time fluorescence quantitative RT-PCR for gene mRNA expression are reliable, and results are comparable and repeatable (Li et al., 2008). In the cited study, PrP mRNA expression was evaluated in the central and peripheral nervous tissues of golden hamster using the real-time quantitative fluorescent dye SYBR Green I, which could be incorporated into double-stranded DNA during PCR product formation. However, SYBR Green I may also combine with non-specific PCR products such as primer dimers. In this study, using optimization of PCR conditions and product melting curve analysis, the occurrence of such a situation was effectively avoided.

Prion-like Doppel protein, sharing 25\% amino acid sequence homology with PrP and whose function remains elusive (Pimenta et al., 2012; Qin et al., 2013), has also been shown to exhibit a high level of expression in a number of cancers including acute myeloid leukemia, myelodysplastic syndrome, gastric adenocarcinoma, anaplastic meningioma and astrocytoma. Whereas $\mathrm{PrP}^{\mathrm{C}}$ is highly expressed in thalamus and cerebrum of the CNS (Wang et al., 2011), Doppel is detected mostly in testes, and its ectopic expression in the CNS leads to ataxia as well as Purkinje and granule cell degeneration in the cerebellum (Didonna et al., 2012).

Doppel regulates male fertility by controlling several aspects of male gametogenesis and sperm-egg interaction, and Doppel expression has high tissue-specificity (Behrens et al., 2002). We found that Doppel mRNA expression was higher in ovary and cerebrum than other tissues in sheep with PRNP ARR/ARQ genotype, moderate in spleen, tonsils, submandibular lymph node and pharynx, and low in other tissues $(\mathrm{P}<0.05)$, which was similar to previous findings (Tranulis et al., 2001).

In recent years, evidence demonstrating antagonistic interaction of prion protein with Doppel has been presented, where the function of Doppel is antagonistic to that of PrP rather than synergistic. (Qin et al., 2006; Sakaguchi, 2008; Li et al., 2009; Sakudo and Onodera, 2011). In this study, PRND mRNA expression levels in the hypothalamus and brain were higher than in cerebellum, spinal cord and brainstem, confirming once again recent studies indicating that Doppel and $\mathrm{PrP}^{\mathrm{C}}$ exhibit mutual antagonism.

Lezmi et al. (2006) analyzed the accumulation of disease-associated prion protein $[\operatorname{PrP}(\mathrm{d})]$ using biochemical and immunohistochemical methods, and the two ARQ/ARQ sheep that had scrapie-like clinical symptoms showed $\operatorname{PrP}(\mathrm{d})$ in the central, sympathetic and enteric nervous systems and in lymphoid organs. In VRQ/VRQ lambs fed with VRQ/VRQ scrapie sheep milk, Doppel was detected in the distal ileum 43 days later and in the lymphatic system 44 days later (Konold et al., 2008). The present findings were similar to previously reported data, where PRND mRNA was higher in ARR/ARQ than ARH/ARQ in brain, colon, ileum, cecum, and uterus, and where PRND mRNA was higher in ARH/ARQ than ARR/ARQ in thalamus and rectum. Our study demonstrated that there are important differences in Doppel expression levels of the digestive system that may be relevant to the mechanism of prion replication and spongiform encephalopathy.

In summary, our study is the first to present absolute quantitative measurement of Doppel mRNA in differential sheep PRNP genotypes. The results on Doppel expression pattern presented here provide valuable baseline data for future studies. 


\section{ACKNOWLEDGMENTS}

Research supported by the National Natural Science Foundation of China (\#31160510), the Doctoral Program of Higher Education Fund (\#20060733006), the Agricultural Biotechnology Research and Application Program in Gansu Province (\#GNSW-2005-11 and \#GNSW2007-004), and the State Key Laboratory of Veterinary Etiological Biology, Lanzhou Veterinary Research Institute, Chinese Academy of Agricultural Sciences (2008-2009).

\section{REFERENCES}

Behrens A, Genoud N, Naumann H, Rulicke T, et al. (2002). Absence of the prion protein homologue Doppel causes male sterility. EMBO J. 21:3652-3658.

Caplazi PA, O’Rourke KI and Baszler TV (2004). Resistance to scrapie in PrP ARR/ARQ heterozygous sheep is not caused by preferential allelic use. J. Clin. Pathol. 57: 647-650.

Didonna A, Sussman J, Benetti F and Legname G (2012). The role of Bax and caspase-3 in doppel-induced apoptosis of cerebellar granule cells. Prion 6: 309-316.

Goldmann W, Hunter N, Foster JD, Salbaum JM, et al. (1990). Two alleles of a neural protein gene linked to scrapie in sheep. Proc. Natl. Acad. Sci. U. S. A. 87: 2476-2480.

Hunter N, Foster JD, Goldmann W, Stear MJ, et al. (1996). Natural scrapie in a closed flock of Cheviot sheep occurs only in specific PrP genotypes. Arch Virol. 141: 809-824.

Konold T, Moore SJ, Bellworthy SJ and Simmons HA (2008). Evidence of scrapie transmission via milk. BMC Vet. Res. 4: 14 .

Lezmi S, Ronzon F, Bencsik A, Bedin A, et al. (2006). PrP(d) accumulation in organs of ARQ/ARQ sheep experimentally infected with BSE by peripheral routes. Acta Biochim Pol. 53: 399-405.

Li A, Sakaguchi S, Shigematsu K, Atarashi R, et al. (2000). Physiological expression of the gene for PrP-like protein, PrPLP/Dpl, by brain endothelial cells and its ectopic expression in neurons of PrP-deficient mice ataxic due to Purkinje cell degeneration. Am. J. Pathol. 157: 1447-1452.

Li YR, Li Q, Yang JM, Zhou XM, et al. (2008). Expression patterns of Doppel gene in golden hamster: quantification using real-time RT-PCR. Mol. Cell Probes 22: 255-258.

Li P, Dong C, Lei Y, Shan B, et al. (2009). Doppel-induced cytotoxicity in human neuronal SH-SY5Y cells is antagonized by the prion protein. Acta Biochim. Biophys. Sin. 41: 42-53.

Makrinou E, Collinge J and Antoniou M (2002). Genomic characterization of the human prion protein ( $\mathrm{PrP})$ gene locus. Mamm. Genome 13: 696-703.

O’Doherty E, Healy A, Aherne M, Hanrahan JP, et al. (2002). Prion protein (PrP) gene polymorphisms associated with natural scrapie cases and their flock-mates in Ireland. Res. Vet. Sci. 73: 243-250.

Pimenta J, Domingos A, Santos P, Marques CC, et al. (2012). Is prt a pseudogene? Identification of ram Prt in testis and ejaculated spermatozoa. PLoS One 7: e42957.

Qin K, O'Donnell M and Zhao RY (2006). Doppel: more rival than double to prion. Neuroscience 141: 1-8.

Qin K, Ding T, Xiao Y, Ma W, et al. (2013). Differential responses of neuronal and spermatogenic cells to the doppel cytotoxicity. PLoS One 8: e82130.

Sakaguchi S (2008). Antagonistic roles of the N-terminal domain of prion protein to doppel. Prion 2: 107-111.

Sakudo A and Onodera T (2011). Tissue- and cell type-specific modification of prion protein (PrP)-like protein Doppel, which affects PrP endoproteolysis. Biochem. Biophys. Res. Commun. 404: 523-527.

Tranulis MA, Espenes A, Comincini S, Skretting G, et al. (2001). The PrP-like protein Doppel gene in sheep and cattle: cDNA sequence and expression. Mamm. Genome 12: 376-379.

Wang C, Wu R, Li FD, Liu L, et al. (2011). Expression patterns of prion protein gene in differential genotypes sheep: quantification using molecular beacon real-time RT-PCR. Virus Genes 42:457-462.

Zhao CL, Wu R, Liu L, Li FD, et al. (2012). Ovine prion protein genotype frequencies in northwestern China. Genet. Mol. Res. 11:1671-1681. 